Research Article

\title{
Solid Particle Erosion of a Limestone Target Surface under Controlled Conditions
}

\author{
Anna Laura Sanna $(\mathbb{D}$, Giorgio Pia $(\mathbb{D}$, and Francesco Delogu $(\mathbb{D}$ \\ Dipartimento di Ingegneria Meccanica, Chimica,e dei Materiali, Università degli Studi di Cagliari, via Marengo 2, \\ Cagliari 09123, Italy \\ Correspondence should be addressed to Giorgio Pia; giorgio.pia@dimcm.unica.it
}

Received 15 September 2020; Revised 30 November 2020; Accepted 3 December 2020; Published 16 December 2020

Academic Editor: José António Fonseca de Oliveira Correia

Copyright (C) 2020 Anna Laura Sanna et al. This is an open access article distributed under the Creative Commons Attribution License, which permits unrestricted use, distribution, and reproduction in any medium, provided the original work is properly cited.

\begin{abstract}
This work focuses on the erodent capability of yttria-stabilized zirconia beads impacting on a limestone target surface. The target surface was used as the cap of a hardened steel vial clamped on a SPEX Mixer/Mill 8000. The vial three-dimensional swing results in repeated bead impacts that cause the material removal from the target surface. The mass loss varies linearly with the number of beads, which allowed estimating the mass lost per bead per impact. It amounts approximately to $70 \mathrm{ng}$, a value that compares fairly well with the one of about $80 \mathrm{ng}$ estimated from the volume of the indents left on the target surface by individual impacts. Experimental findings indicate that the methodology developed can be reliably utilized to investigate solid particle erosion under highly reproducible and controllable experimental conditions.
\end{abstract}

\section{Introduction}

Solid particle erosion (SPE) is a typical erosion wear mode involving the progressive removal of material from a solid surface due to the repeated impact of small solid particles [1]. Although it finds important application in abrasive blasting processes such as sandblasting and abrasive water-jet cutting [2], SPE is mostly an undesired phenomenon that gives rise to serious problems in many engineering environments involving the flow of fluids entraining tiny granular hard matter. For instance, it is a leading factor in the failure and replacement of turbines, pipelines, valves, and reactors [3].

Owing to its severe economic impact throughout modern industry, SPE containment and control are of the upmost relevance. Significant resources have been spent to investigate and study SPE to such aim, which resulted in a vast literature concerning SPE application to engineering materials $[4,5]$. Performed studies indicate that SPE is sensitive to particle and surface properties as well as to particle impingement conditions [1]. In particular, the rate of mass loss is prominently affected by surface ductility [1]. Whereas ductile materials undergo a multistage SPE, the response of brittle materials is governed by crack formation $[1,6-12]$.

Scarce information is available regarding rock materials. Typically, minerals split along cleavage planes of relative weakness if present [13-18]. Otherwise, particle impingement generates lateral and radial cracks that progressively grow upon subsequent impacts at rates depending on tensile strength. Once cracks intersect, small pieces of material got separated from the surface and are removed by impinging particles [13-18]. The volume of eroded material increases with the impinging particle diameter $[19,20]$, and local heating processes can be inferred from schist SPE $[21,22]$. In addition, the increase in fracture toughness reduces relative erosion according to a reverse power law that is affected by the impingement velocity [23].

In this work, we investigate the SPE behaviour of limestone, a rock commonly used as a building material in historical constructions all over the coastal regions of Sardinia. Due to its position in the middle of the Mediterranean Sea, Sardinia is particularly windy and buildings suffer from wind erosion. Wind carries along grains of sand at high speed, and these behave as very effective tools that sandblast 
away limestone by abrasion [24-26]. A deeper knowledge of SPE would certainly help in identifying the most suitable strategy to oppose the undesired degradation of the rock and address protection and restoration of historical buildings.

To this aim, we propose a novel methodology based on the use of a ball mill usually utilized to blend and grind granular bodies on the laboratory scale. The ball mill is equipped with a cylindrical vial. We replaced the original screw-on cap of the vial with a limestone cap and placed a certain number of particles of selected size into the vial. Once the vial is locked on the clamp, the mill shakes it along a complex trajectory that induces particle impacts on the limestone cap, which works as the target surface for SPE. Impacts take place under controlled conditions, no longer determined by the flow of a carrier fluid but, rather, by the periodic vial swings. Processing conditions can be easily adjusted to investigate SPE over long times in the presence of a significant number of particles as well as to study individual impacts of a single particle. In all cases, the eroded material remains within the reactor and its mass can be readily determined, which allows establishing a direct link between mass loss and number and energy of particle impacts. In particular, the mass eroded per impact has been reliably estimated.

Experimental methodologies are described in detail in the following. Full details are given in Supplementary Information (SI).

\section{Experimental Outline}

2.1. Materials. Experiments have been performed using limestone as the target surface. The limestone utilized is a bioclastic calcarenite deriving from quarries nearby the village of Santa Caterina di Pittinurri, on the East coast of Sardinia. Its mineral composition is relatively simple. Calcite predominates over other carbonate minerals such as ankerite, dolomite, and muscovite. Quartz is also present. Vickers hardness is equal to about $2.4 \mathrm{GPa}$.

Target surfaces were prepared cutting off circular caps about $10 \mathrm{~mm}$ in diameter from a limestone slab about $5 \mathrm{~mm}$ thick. Limestone caps were suitably polished to have the two circular surfaces perfectly parallel to each other. Any residual particulate was removed by subjecting the caps to gentle cleaning by ultrasounds.

Yttria-stabilized zirconia beads have been chosen as the erodent material. Beads are approximately spherical, with a diameter of about $1 \mathrm{~mm}$ and Vickers hardness of about 13.2 GPa. Thus, they are significantly harder than limestone. The number of beads used in experiments has been varied from 1 to 5 and to 10 in the attempt of pointing out possible effects of multiple impingements on SPE.

2.2. Methods. Beads were placed in a container consisting of a hardened tool steel cylinder with outer and inner diameters equal to about 2.4 and $1.9 \mathrm{~cm}$, respectively, and the inner height of about $5.8 \mathrm{~cm}$. Polished limestone caps were used to replace the original hardened-toll-steel screw-on caps equipped with O-rings that allow sealing the vial. The limestone cap was leaned against the top end of the container and clamped with the threaded aluminium cap as shown in Figure 1 (see SI.1 for details). The vial was placed in the clamp of a SPEX Mixer/Mill 8000, and the clamp tightened and locked.

The SPEX Mixer/Mill 8000 is a compact laboratory mechanical device that is functionally described as a highenergy ball mill. In the light of its widespread use in materials science and mechanochemistry [27, 28], its mechanics has been studied in great detail [29-32]. The device shakes the vial along the complex trajectory schematically described in Figure 2. The vial movement results from the combination of a harmonic oscillation on the vertical plane with a partial rotation along the axis perpendicular to the vial main axis and passing through the geometrical centre of its inner cylindrical volume. Harmonic and lateral swings sweep an angle of about $15^{\circ}$ and take place at a frequency of about 14.6 Hz (see SI.2 for details).

Each swing makes the beads impact with each other and against ends and cylindrical walls of the vial. Impact velocity depends on the mill frequency as well as on the bead dynamics. A relatively large number of beads can give rise to a strongly dissipative dynamics that result in the cooperative motion of the granular body. Under such circumstances, the effects of individual bead impacts on the limestone target surface cannot be evaluated. Therefore, we opted to work with 1,5 , and 10 yttria-stabilized zirconia beads. In this way, we have been able to estimate the frequency and velocity of impacts on the limestone cap and to study their effects in detail.

Two different methods have been utilized to estimate the frequency and velocity of impacts. On the one hand, we used a transparent glass cylinder to perform high-speed video recording of bead dynamics during the mill operational cycle, which enabled the study of individual bead trajectories. On the other, we carried out calculations to numerically reconstruct the bead trajectories starting from the analytical description of the three-dimensional vial swing. High-speed video recording was performed using a CASIO Exilim F1 video camera. Videos have been recorded at $600 \mathrm{fps}$ and suitably analysed to estimate the frequency and velocity of impacts on the limestone cap (see SI.3 for details). Numerical simulations were performed using a FORTRAN simulation code. The vial swing was described with respect to an inertial Cartesian reference frame centred on the eccentric fulcrum of the mechanical arm that clamps the vial [29-32]. Simultaneously, the dynamics of beads inside the vial was reproduced using a noninertial Cartesian reference frame moving with the reactor and with the origin at its centre [29-32]. Contacts between beads and vial walls were described within the framework of the discrete element method [33] (see SI.4 for details).

High-speed video recording and numerical simulations provided detailed information on bead trajectories as well as on impact angles and velocities. Individual beads follow a relatively regular trajectory dominated by the main harmonic swing on the vertical plane. Rebounds on the cylindrical wall determine sudden changes in direction without affecting the periodic displacement between the 


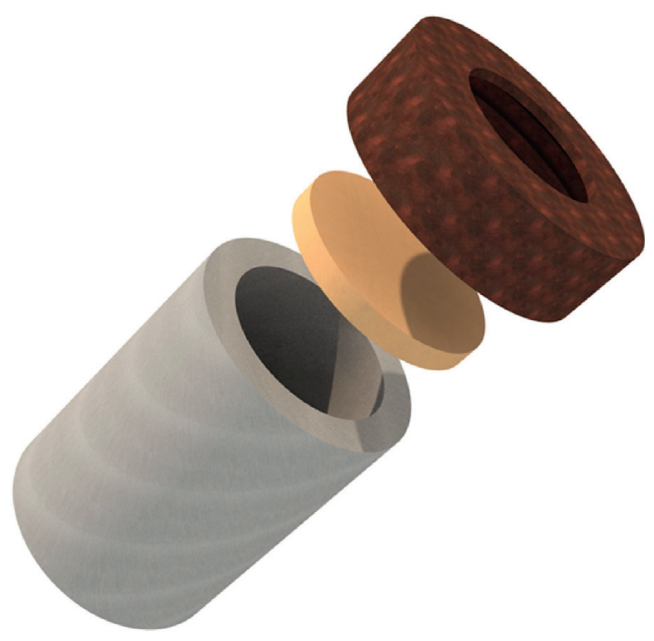

(a)

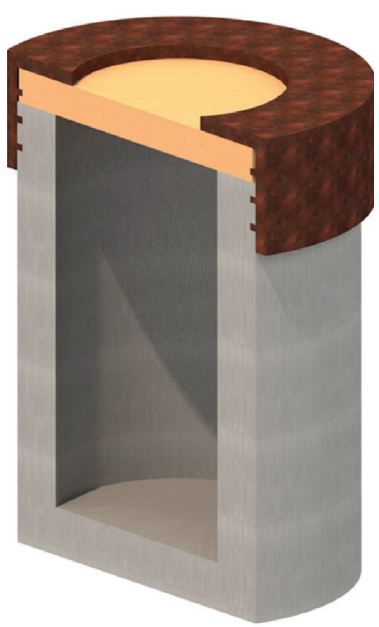

(b)

Figure 1: (a) The exploded view and (b) a cross section of the vial.

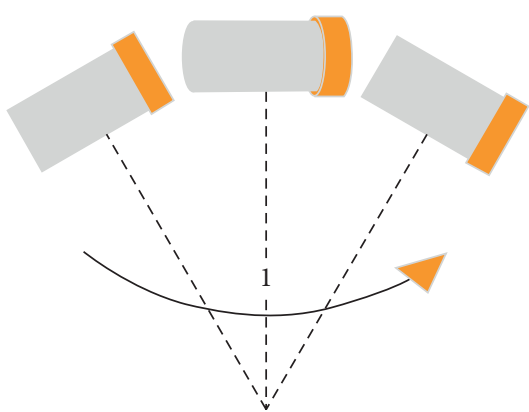

(a)

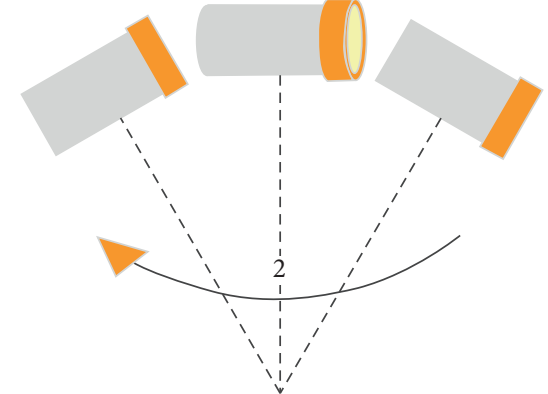

(b)

Figure 2: A schematic description of the vial motion. The vial moves between the two extreme points of its swing in the first half cycle (1), and then it comes back to the initial point in the second half cycle (2). Lateral movements make the vial assume opposite orientations at the midpoint of each half cycle.

opposite vial ends. Typically, impact angles vary between $50^{\circ}$ and $70^{\circ}$, whereas impact velocity ranges from 3 to $5 \mathrm{~m} \cdot \mathrm{s}^{-1}$ (see SI.5 for details).

After each experimental run, the vial was opened and carefully emptied. Container, limestone cap, and beads were suitably handled to remove and collect any particulate deriving from the SPE of the target surface. Whenever in sufficient amount, the collected particulate was weighed using a laboratory precision balance able to read four decimal places to the right of the decimal point.

Optical microscopy was used to inspect the target surface and identify interesting portions. Subsequently, a microtome was utilized to cut off the identified portions of the eroded surface. Their morphology on the microscopic scale was investigated by scanning electron microscopy (SEM) using a Zeiss EVO LS15 microscope. To this aim, samples were properly coated with $\mathrm{Au}$ to create a conductive metal layer enabling a satisfactory imaging of the sample surface. SEM micrographs were used for counting the indents left by the impacts of individual beads.

\section{Results and Discussion}

Bead impacts on the limestone target surface determine its gradual erosion. Measured by repeated weighing with the laboratory precision balance, the total mass lost by the limestone cap in the various experimental runs, $\Delta m$, is shown in Figure 3 as a function of time, $t$. Data clearly indicate that $\Delta m$ varies linearly with $t$. The slopes of linear plots measure the rates at which bead impacts erode the target surface. Best-fitting the experimental points with straight lines results in rates approximately equal to 0.435 , 0.257 , and $0.051 \mathrm{mg} \cdot \mathrm{min}^{-1}$ for experiments performed with 10,5 , and 1 beads, respectively.

In experimental runs with 10 and 5 beads, SPE proceeds at rates about 10 and 5 times higher than the one estimated in experiments with a single bead. This strongly suggests that the frequency of impacts on the limestone cap varies linearly with the number of beads, and that individual impacts have substantially the same effects in the presence of 1,5 , or 10 beads. Therefore, the three rate values can be used to 


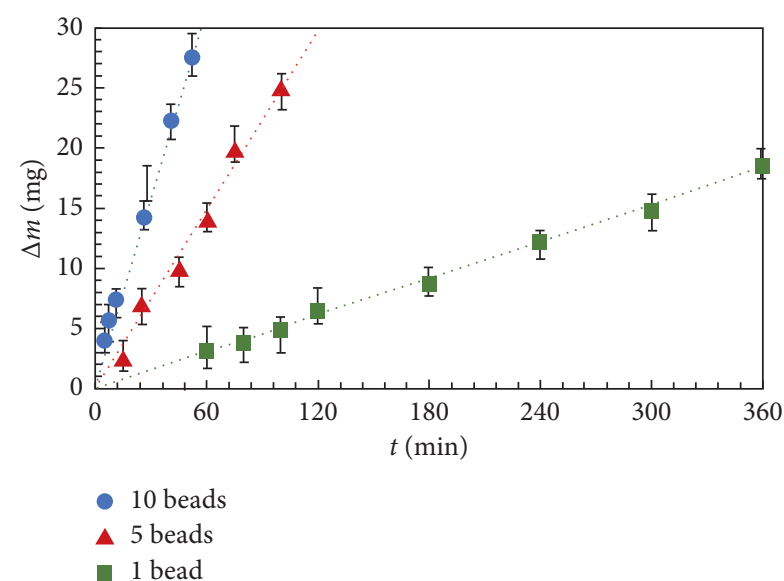

Figure 3: The total mass lost by the limestone cap, $\Delta m$, as a function of time, $t$. Best-fitted lines are shown.

calculate the average SPE rate due to a single bead. In particular, it is sufficient to average over the three SPE rates each normalized to the proper number of beads used in the experiment. The resulting value of $0.048 \mathrm{mg} \cdot \mathrm{min}^{-1}$ measures the rate of mass loss undergone by the limestone target surface in the presence of a single erodent bead.

This value can be used to estimate the mass loss ascribable to individual impacts. To this aim, an estimate of the impact frequency on the target surface is needed. Such estimate was easily obtained from high-speed video recording of individual bead trajectories within a shaken transparent vial as well as from numerical simulation of the bead dynamics.

High-speed video recording allows satisfactorily visualizing the dynamics of individual beads inside the moving container (see SI. 3 for detail). Overall, 10 and 5 beads do not show any tendency to exhibit dissipative dynamics. Accordingly, they move independent of each other, sampling all the volume available inside the vial. It follows that in experiments using a total of 5 and 10 beads, each bead exhibits approximately the same behaviour it would display in the absence of other beads. Experiments performed with a single bead clearly indicate that it moves between the two opposite vial ends following relatively regular trajectories. On the average, a single bead impacts onto the limestone target surface with a frequency of about $11.6 \mathrm{~Hz}$. Accordingly, the limestone cap is hit by the bead approximately 0.8 times per cycle of the vial swing.

The outcomes of numerical simulations confirm the scenario described above. In simulations involving 5 and 10 beads, the single beads follow similar trajectories independent of each other, except for rare bead-bead impacts, which make the bead travel regularly between the opposite vial ends. Again, it appears that each bead hits the limestone cap 0.8 times per cycle on the average (see SI.4 for details).

Experiments carried out with a single bead allow relating the measured SPE rate with the total number of individual bead impacts. In turn, this enables the evaluation of the limestone eroded, on the average, in individual impacts. Simple calculations show that a single impact is able to remove about $68 \mathrm{ng}$ from the limestone target surface.

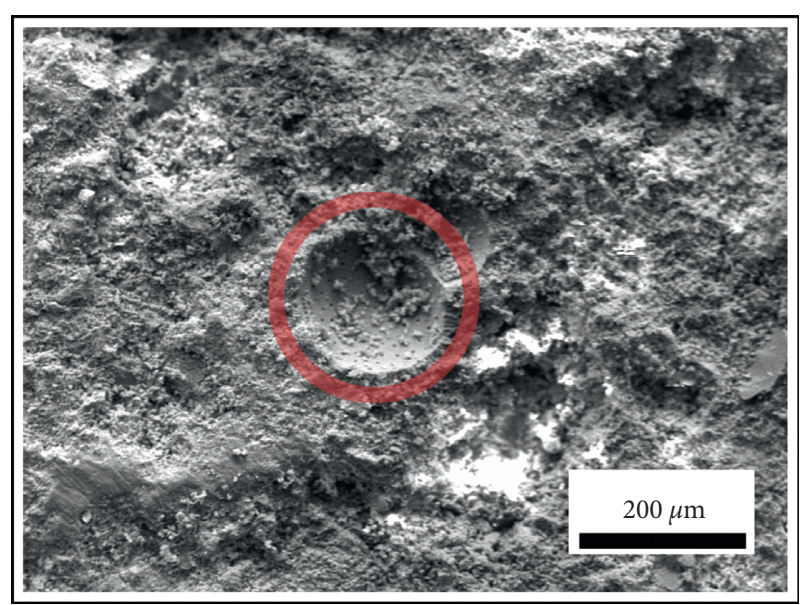

FIgURE 4: SEM micrograph of a typical indent generated by the impact of a yttria-stabilized zirconia bead on the limestone target surface.

SEM observation of the indents generated by individual bead impacts on the limestone target surface supports such result. Specifically, pristine, finely polished limestone caps were used as target surfaces in the presence of a single bead. The ball mill was operated for times short enough to allow only a few bead impacts on the limestone. In this way, the target surface exhibits just a few, well-defined indents such as the one shown in Figure 4. Indents have the shape of a spherical cap. Invariably, their characteristic lengths are similar, with a radius of the base of the cap of about $50 \mu \mathrm{m}$.

This suggests that yttria-stabilized zirconia beads are hard enough to indent the limestone cap and concomitantly remove the material involved. As shown in Figure 5, beads are not affected by impacts. Only after a significant number of impacts, their surface starts losing the initial pearl white appearance.

The volume of the spherical cap left behind by bead impacts provides an independent measure of the amount of material removed by individual impacts. A schematic picture of a bead indenting the surface is shown in Figures 6(a) and 6(b). Assuming a radius of the base of the cap of $75 \mu \mathrm{m}$, the spherical cap is approximately $5.7 \mu \mathrm{m}$ high. Its volume is equal to about $50.1 \times 10^{3} \mu \mathrm{m}^{3}$. Since the limestone density is about $1.66 \mathrm{~g} \cdot \mathrm{cm}^{-3}$, the mass loss associated with the formation of the indent is approximately equal to $83 \mathrm{ng}$. Taking into due account the experimental uncertainties that affect the evaluation, this estimate is quite close to the one of $68 \mathrm{ng}$ obtained by measuring the mass lost by the limestone cap using the laboratory precision balance.

The material removed by SPE from the limestone target surface was characterized using optical microscopy and SEM observation. Typical micrographs are shown in Figure 7. Optical microscopy under polarized light conditions indicates that the eroded material consists of small powder particles about $3 \mu \mathrm{m}$ in size. Although electrostatic phenomena tend to agglomerate particles into much larger aggregates, SEM observation confirms that powder particles have size ranging between 2 and $5 \mu \mathrm{m}$. Under the simplifying assumption that particles have a spherical shape and a $3 \mu \mathrm{m}$ 


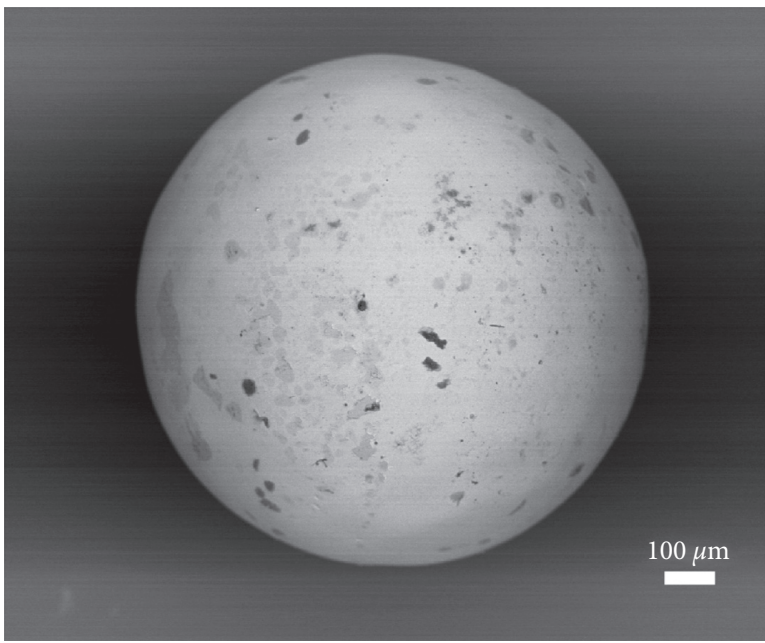

(a)

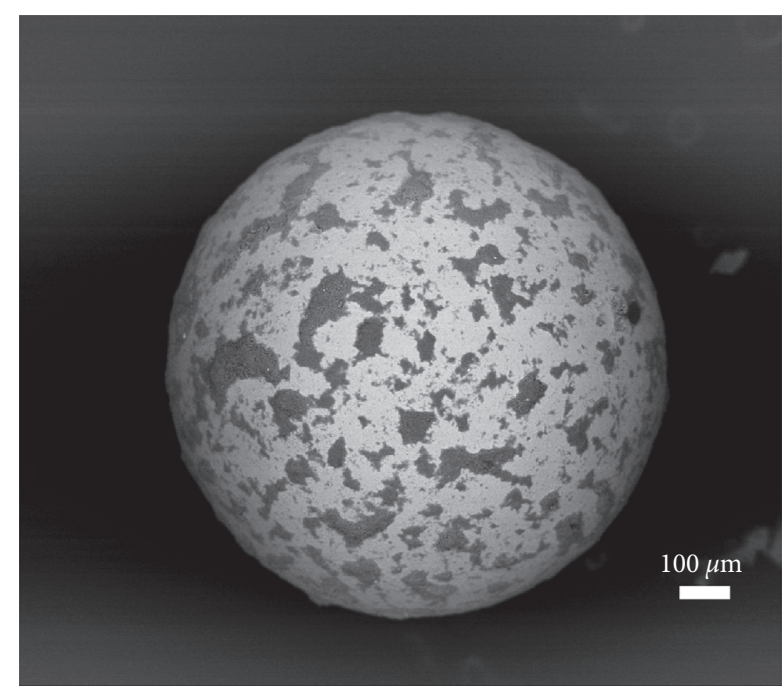

(b)

FIGURE 5: SEM micrographs of a yttria-stabilized zirconia bead (a) before and (b) after 300 min of mill operation.

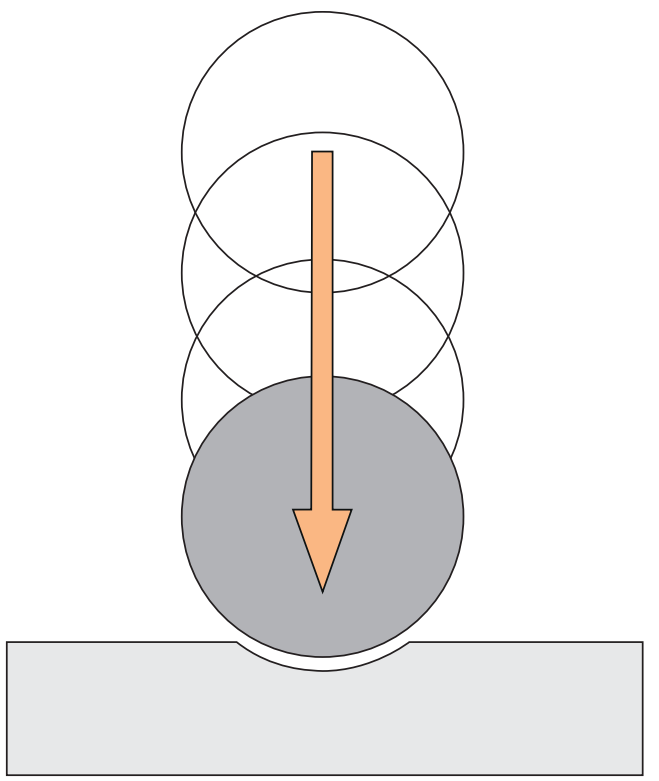

(a)

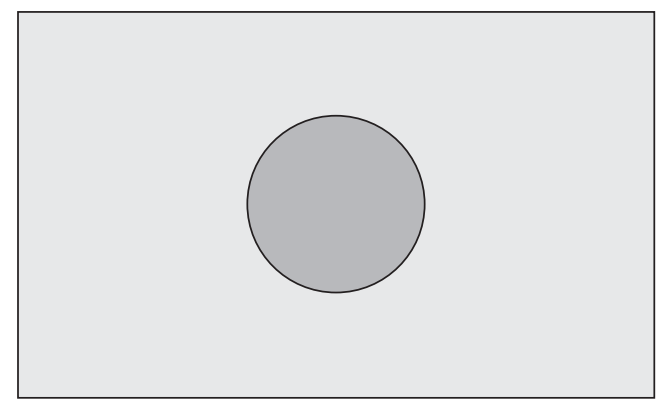

(b)

FIgURE 6: A schematic picture of a bead (a) indenting the surface (b).

diameter, the formation of indent on the limestone target surface in individual bead impacts induces the generation of about 100 powder particles. This fine particulate does not hinder the bead dynamics, at least within the time intervals explored by the present study.

Following the literature [23], we estimated the mass of eroded material in individual bead impacts according to a model based on impact-induced crack formation in brittle solids [34]. The model expresses the mass loss as

$$
\Delta \mathbf{m} \approx 0.41 \rho\left\{\left(\pi \mathbf{c}_{\mathrm{I}} \tan \beta\right)^{-2}\left[\frac{\left(\mathbf{m}_{\mathbf{b}} \mathbf{v}^{2}\right)^{14}}{\mathbf{K}^{12} \boldsymbol{\sigma}^{2}}\right]^{1 / 12}\right\},
$$

where $\boldsymbol{\rho}$ is the limestone density, $\mathbf{c}_{\mathbf{I}}$ is an empirical parameter, $\boldsymbol{\beta}$ is the indentation angle, $\mathbf{m}_{\mathbf{b}}$ is the bead mass, $\mathbf{v}$ is the impact velocity, $\mathbf{K}$ is the limestone fracture toughness, and $\boldsymbol{\sigma}$ is the limestone yield strength. The quantity characteristics of limestone are known from the literature (see 


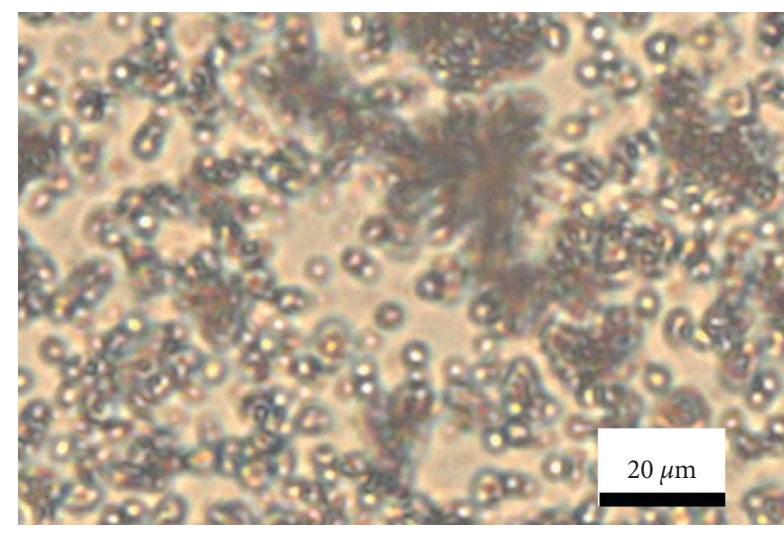

(a)

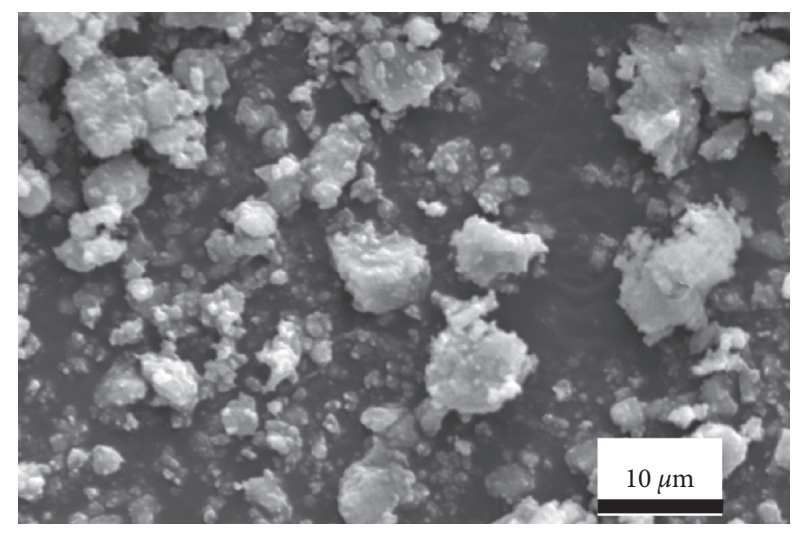

(b)

FIgURE 7: (a) Optical microscopy image of eroded material under exposure to polarized light and (b) SEM micrograph of powder particles.

SI.6 for details). Therefore, the mass loss predicted by the model for different $\mathbf{v}$ values can be readily calculated.

The obtained $\Delta \mathbf{m}$ estimates are significantly larger than the experimental one of about $70 \mathrm{ng}$. Even for an impact velocity of $0.5 \mathrm{~m} \cdot \mathrm{s}^{-1}$, which can be regarded as the lowest bound of impact velocity distribution, the predicted mass loss is as large as $2.2 \mu \mathrm{g}$, i.e., approximately three times the experimental value. At the most probable impact velocity of $4 \mathrm{~m} \cdot \mathrm{s}^{-1}$, the predicted $\Delta \mathrm{m}$ value increases up to $28 \mathrm{mg}$.

About three orders of magnitude separate experimental and theoretical estimates. To a first approximation, this can be ascribed to the different ranges of impact velocity explored in our experiments and taken into account in the development of models addressing typical abrasive blasting conditions. In fact, in the latter case, SPE takes place under the effect of impact velocities as high as $200 \mathrm{~m} \cdot \mathrm{s}^{-1}$. Thus, it appears that our methodology allows investigating reliably SPE processes mediated by much less energetic impacts and involving significantly smaller eroded masses.

In this regard, it is here worth noting that the methodology is, in principle, quite flexible. The SPEX Mixer/Mill 8000 can be equipped with electric motors enabling the variation of the vial swing frequency within a broad range of values. Previous work has shown that working frequencies can range approximately from $11 \mathrm{~Hz}$ to $25 \mathrm{~Hz}[30,35]$. Thus, impact velocities can be varied accordingly, and impact angles can be controlled by varying the incline of the target surface. The mass of impinging particles and their number can be controlled as well. In addition, experiments can be performed under vacuum conditions, i.e., in the absence of any gaseous atmosphere. Overall, the use of polished caps made of geomaterials as target surface shows the promise of facilitating experimental investigation in the field of SPE and the acquisition of new details on the effects of individual impacts.

\section{Conclusions}

Experiments aimed at evaluating SPE on a limestone target surface have been performed using a SPEX Mixer/Mill 8000. The three-dimensional swing of the clamped vial allowed inducing repeated impacts of yttria-stabilized zirconia beads on the polished limestone cap utilized to close the hardened steel cylindrical container. Impacts resulted in the removal of material from the target surface. The mass loss is directly proportional to the number of beads. Direct evidence from experiments performed using single or more beads indicates that individual impacts remove about $70 \mathrm{ng}$ of material. This value compares remarkably well with the estimate of about $80 \mathrm{ng}$ obtained from the volume of indents left on the target surface by individual impacts. Overall, SPE of limestone finally results in the removal of about a hundred $3-\mu \mathrm{m}$ particles of eroded material per impact.

The methodology utilized allows studying SPE in great detail. It enables highly reproducible experiments with considerable control of processing conditions. In principle, impact velocity can be varied over a quite broad range simply changing the frequency of the vial three-dimensional swing. The number and size of erodent particles can be changed, and their effects on the target surface can be accurately investigated. Indeed, the use of a closed vial allows collecting the total mass of eroded material and weighing it for a quantitative evaluation of the SPE rate.

Overall, the methodology developed is flexible enough to be extended to other ball mills and to a variety of erodent and eroded materials combinations. Further work is ongoing to explore potential and limitations of the methodology.

\section{Data Availability}

All data used to support the findings of this study are included within the article.

\section{Conflicts of Interest}

The authors declare that they have no conflicts of interest.

\section{Acknowledgments}

This study was funded by the University of Cagliari, grant number RICCAR_2012_Delogu. 


\section{Supplementary Materials}

SI.1: limestone caps. Figure SI.1.1: original samples and circular caps fabricated from slabs. Figure SI.1.2: vial components. SI.2: ball mill dynamics and vial motion Figure SI.2.1: picture of the SPEX Mixer/Mill 8000. SI.3: high-speed video recording. SI.4: bead dynamics and milling conditions. SI.5: statistical distributions of impact angles and impact velocities Figure SI.5.1: statistical distributions $p$ of (a) impact angle, $b$, and (b) total impact velocity, $v$. SI.6: model calculations Figure SI.6.1: the mass lost by the limestone cap, $\mathrm{Dm}$, as a function of the impact velocity, $v$. (Supplementary Materials)

\section{References}

[1] M. Parsi, K. Najmi, F. Najafifard, S. Hassani, B. S. McLaury, and S. A. Shirazi, "A comprehensive review of solid particle erosion modeling for oil and gas wells and pipelines applications," Journal of Natural Gas Science and Engineering, vol. 21, pp. 850-873, 2014.

[2] M. Islam, W. McGaulley, and M. Evans, "A review of abrasive waterjetting (AB-WJ)," in Proceedings of the Ultra High Pressure Abrasive Blasting (UHP-AB) and Other Emerging Technologies for Coating Removal and Surface Preparation, Proceedings of the 2005 Tri Service Corrosion Conference, Orlando, FL, USA, November 2005.

[3] A. V. Levy, Solid Particle Erosion and Erosion-Corrosion of Materials, ASM International, Materials Park, OH, USA, 1995.

[4] A. W. Momber and R. Kovacevic, Principles of Abrasive Water Jet Machining, Springer, London, UK, 1998.

[5] A. W. Momber, Blast Cleaning Technology, Springer, London, UK, 2008

[6] S. Srinivasan and R. O. Scattergood, "Effect of erodent hardness on erosion of brittle materials," Wear, vol. 128, no. 2, pp. 139-152, 1988.

[7] M. Antonov, J. Pirso, A. Vallikivi, D. Goljandin, and I. Hussainova, "The effect of fine erodent retained on the surface during erosion of metals, ceramics, plastic, rubber and hardmetal," Wear, vol. 354-355, pp. 53-68, 2016.

[8] M. Antonov, D.-L. Yung, D. Goljandin, V. Mikli, and I. Hussainova, "Effect of erodent particle impact energy on wear of cemented carbides," Wear, vol. 376-377, pp. 507-515, 2017.

[9] G. Hao, X. Dong, M. Du, Z. Li, and Z. Dou, “A comparative study of ductile and brittle materials due to single angular particle impact," Wear, vol. 428-429, pp. 258-271, 2019.

[10] M. M. Kou, Y. J. Lian, and Y. T. Wang, "Numerical investigations on crack propagation and crack branching in brittle solids under dynamic loading using bond-particle model," Engineering Fracture Mechanics, vol. 212, pp. 41-56, 2019.

[11] G. Sundararajan, "A comprehensive model for the solid particle erosion of ductile materials," Wear, vol. 149, no. 1-2, pp. 111-127, 1991.

[12] I. Kleis and P. Kulu, Solid Particle Erosion Occurrence, Prediction and Control, Springer-Verlag, London, UK, 2008.

[13] P. N. W. Verhoef, T. J. Kuipers, and W. Verwaal, "The use of the sand-blast test to determine rock durability," Bulletin of the International Association of Engineering Geology, vol. 29, no. 1, pp. 457-461, 1984.

[14] P. N. W. Verhoef, "Sandblast testing of rock," International Journal of Rock Mechanics and Mining Sciences \& Geomechanics Abstracts, vol. 24, no. 3, pp. 185-192, 1987.
[15] X. Cai, Z. He, S. Tang, and X. Chen, "Abrasion erosion characteristics of concrete made with moderate heat Portland cement, fly ash and silica fume using sandblasting test," Construction and Building Materials, vol. 127, pp. 804-814, 2016.

[16] A. W. Momber, "Damage to rocks and cementitious materials from solid impact," Rock Mechanics and Rock Engineering, vol. 37, no. 1, pp. 57-82, 2004.

[17] Y. I. Oka, K. Okamura, and T. Yoshida, "Practical estimation of erosion damage caused by solid particle impact," Wear, vol. 259, no. 1-6, pp. 95-101, 2005.

[18] Y. I. Oka, T. Yoshida, and T. Yoshida, "Practical estimation of erosion damage caused by solid particle impact," Wear, vol. 259, no. 1-6, pp. 102-109, 2005.

[19] M. Cui, Y.-H. Zhai, and G.-D. Ji, "Experimental study of rock breaking effect of steel particles," Journal of Hydrodynamics, vol. 23, no. 2, pp. 241-246, 2011.

[20] Y. Du, R. Wang, and H. Ni, "Feasibility of particle jet as a drilling medium for the development of deep complicated oilgas reservoir," Advanced Materials Research, vol. 361-363, pp. 465-468, 2012.

[21] A. W. Momber, "Erosion of schist due to solid particle impingement," Rock Mechanics and Rock Engineering, vol. 46, no. 4, pp. 849-857, 2013.

[22] A. W. Momber, "Effects of target material properties on solid particle erosion of geomaterials at different impingement velocities," Wear, vol. 319, no. 1-2, pp. 69-83, 2014.

[23] A. W. Momber, "Fracture toughness effects in geomaterial solid particle erosion," Rock Mechanics and Rock Engineering, vol. 48, no. 4, pp. 1573-1588, 2015.

[24] Y. Shao, "Physics and modelling of wind erosion," Atmospheric and Oceanographic Sciences Library, Springer, Dordrecht, Netherlands, 2008.

[25] W. Jia, C. Zhang, X. Zou et al., "Effects of ridge height and spacing on the near-surface airflow field and on wind erosion of a sandy soil: results of a wind tunnel study," Soil and Tillage Research, vol. 186, pp. 94-104, 2019.

[26] M. Jarrah, S. Mayel, J. Tatarko, R. Funk, and K. Kuka, "A review of wind erosion models: data requirements, processes, and validity," Catena, vol. 187, p. 104388, 2020.

[27] C. Suryanarayana, "Mechanical alloying and milling," Progress in Materials Science, vol. 46, no. 1-2, pp. 1-184, 2001.

[28] P. Baláž, M. Achimovičová, M. Baláž et al., "Hallmarks of mechanochemistry: from nanoparticles to technology," Chemical Society Reviews, vol. 42, pp. 7571-7637, 2013.

[29] C. Caravati, F. Delogu, G. Cocco, and M. Rustici, "Hyperchaotic qualities of the ball motion in a ball milling device," Chaos: An Interdisciplinary Journal of Nonlinear Science, vol. 9, no. 1, pp. 219-226, 1999.

[30] F. Delogu, L. Schiffini, and G. Cocco, "The invariant laws of the amorphization processes by mechanical alloying," Philosophical Magazine A, vol. 81, no. 8, pp. 1917-1937, 2001.

[31] G. Manai, F. Delogu, and M. Rustici, "Onset of chaotic dynamics in a ball mill: attractors merging and crisis induced intermittency," Chaos: An Interdisciplinary Journal of Nonlinear Science, vol. 12, no. 3, pp. 601-609, 2002.

[32] F. Delogu and L. Takacs, "Information on the mechanism of mechanochemical reaction from detailed studies of the reaction kinetics," Journal of Materials Science, vol. 53, no. 19, pp. 13331-13342, 2018.

[33] G. Manai, F. Delogu, L. Schiffini, and G. Cocco, "Mechanically induced self-propagating combustions: experimental findings 
and numerical simulation results," Journal of Materials Science, vol. 39, no. 16/17, pp. 5319-5324, 2004.

[34] X. Chen, J. W. Hutchinson, and A. G. Evans, "The mechanics of indentation induced lateral cracking," Journal of the American Ceramic Society, vol. 88, no. 5, pp. 1233-1238, 2005.

[35] G. Cocco, F. Delogu, and L. Schiffini, "Toward a quantitative understanding of the mechanical alloying process," Journal of Materials Synthesis and Processing, vol. 8, no. 3/4, pp. 167-180, 2000 . 